\title{
DISCLAIMER
}

This report was prepared as an account of work sponsored by an agency of the United States WSRC-MS- -91-377 Government. Neither the United States Government nor any agency thereof, nor any of their employees, makes any warranty, express or implied, or assumes any legal liability or responsibility for the accuracy, completeness, or usefulness of any information, apparatus, product, or process disclosed, or represents that its use would not infringe privately owned rights. Reference herein to any specific commercial product, process, or service by trade name, trademark, manufacturer, or otherwise does not necessarily constitute or imply its endorsement, recommendation, or favoring by the United States Government or any agency thereof. The views and opinions of authors expressed herein do not necessarily state or reflect those of the United States Government or any agency thereof.

\section{THE EFFECT OF SURFACE GAS INJECTION ON FILM BOILING HEAT TRANSFER (U)}

by

M. R. Duignan, et al.

Westinghouse Savannah River Company

Savannah River Site

Aiken, South Carolina 29808

This is a paper for presentation at the

1992 National Heat Transfer Conference and Exposition

San Diego, California

August $9-12,1992$

and publication in the proceedings

This paper was prepared in connection with work done under Contract No. DE-AC09-89SR18035 with the U.S. Department of Energy. By acceptance of this paper, the publisher and/or recipient acknowledges the U.S. Government's right to retain a nonexclusive, royalty-free license in and to any copyright covering this paper, along with the right to reproduce and to authorize others to reproduce all or part of the copyrighted paper.

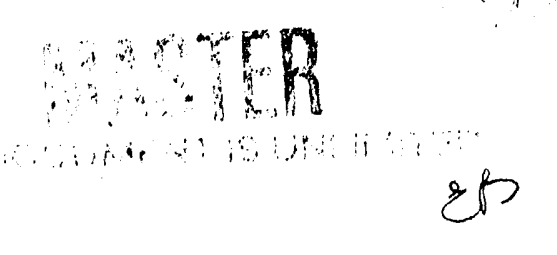




\title{
THE EFFECT OF SURFACE GAS INJECTION ON FILM BOILING HE.AT TRANSFER (U)
}

\author{
M. R. Duignan \\ G. A. Greene
}

Westinghouse Savannah River Co. Brookhaven National Laboratory

Aiken, South Carolina

Upton, New York

T. F. Irvine, Jr.

State University of New York at Stony Brook

Stony Brook, New York

\section{ABSTRACT}

A Database was developed for heat transfer from a horizontal plate with both film boiling and gas jetting occurring simultaneously, in a pool of water maintained at its saturation temperature. The effect of passing nitrogen through established film boiling is to increase the heat transfer from that surface. At the highest superficial gas velccity measured, approximately $8.5 \mathrm{~cm} / \mathrm{s}$, and for a constant surface temperature, the heat transfer increases by a factor of two over the heat transfer with no enhancement by gas flux. Further, as the superficial gas velocity approached zero, the data approach the stable film boiling asymptote. A semi-empirical model was developed and correlated to the database. The result is an equation which represents better than $90 \%$ of all the measured data within $\pm 15 \%$ bounds.

\section{INTRODUCTION}

With the advent of nuclear power reactors as an option to the dwindling sources of fossil fuels for maintaining and increasing the amount of energy used today, safety from accidents of such reactors has become of utmost concern to the public. Safety can only be obtained by understanding the physical phenomena that 
would occur during such accidents. One specific type of accident would be the failure of the reactor's pressure vessel, leading to the deposition of molten core debris into the reactor cavity. Because the cavity of the reactor is made of concrete, it would immediately be attacked by the molten core debris, releasing non-condensible gases into the molten pool.

The design of existing light water reactors allows the introduction of water into the reactor cavity. This increases the release rate of heat from the molten core debris reducing the core temperature and, thus, the danger over a reduced time. The introduction of water into the reactor cavity sets up a new heat-transfer environment which is, at present, unknown. That is, the effect of the gas, which is being released from the concrete cavity and bubbling through the molten core debris, on the heat transfer between the molten pool and the water as the gas passes through the core/water interface.

Blose et al. [1] pointed out that, at least withinareactor safety community, there is no consistent pattern for modeling water pools overlying core debris. They carried out an experiment in which they poured water onto a molten stainless-steel pool, contained in a concrete vessel. They observed the heat transfer environment as a molten core attacked a concrete basemat while being cooled by an overlying pool of water. At that time the effects of non-condensible gases, released from the concrete, on the heat transfer [from the molten pooi to the water pool] were not known. Not knowing how the gas would affect the core-to-water heat transfer the investigators neglected that effect when analyzing their results, and concluded that only nucleate boiling could have occurred on the core-water interface. To have concluded otherwise meant that film boiling was the heat transfer mechanism on the interface. Assuming that stable film boiling had occurred during the experiment the investigators determined that the core interface temperature had to be above the melting point of the stainless steel. Since the upper surface of the molten steel core was determined to have been a solid porous crust during the experiment, the crust temperature had to be lower than 
the melting temperature of stainless steel: therefore, stable film boiling was not possible.

As illustrated in Duignan [2], if Blose et al. [1] had been able to include the effect of the non-condensible gas on the core-water interface heat transfer [using the results of this present study] they could have concluded that film boiling was a possibility. The effect of the gas is to increase the interfacial heat transfer such that the interfacial temperature is below the melting temperature of stainless steel.

The primary reason for this investigation was to develop a database on heat transfer from gas-flux-enhanced film boiling. To obtain the database an experimental apparatus was constructed in which film boiling could be sustained on a horizontal flat surface while a non-condensible gas emerged from that surface. Moreover, to facilitate use of this database on gas-flux-enhanced film boiling a semi-empirical model was developed and correlated with the data.

\section{EXPERIMENTAL APPARATUS}

\section{Overview}

The purpose of the experiment was to determine the effect on film boiling heat transfer from a horizontal, flat cylindrical disk when a non-condensible gas, $99.996 \%$ pure nitrogen, was passed through the vapor film. An overall schematic of the experimental apparatus in shown in Fig. 1.

Heat was sent through the heat transfer surface into the overlying pool of water by means of a flexible electric heater. The pool of water was contained in a cylindrical quartz tube which sat directly above the stainless-steel heat transfer surface, and the pool was maintained at atmospheric pressure and the saturation temperature. Measurement of the heat flux to the pool was made by thermocouples embedded in the heat transfer plate and by 
measuring the mass flux of liquid water as it condensed in the condensing system.

Finally, the pertinent data were read by a data acquisition system to facilitate precise and accurate information. An explanation of the various aspects of the experiment apparatus follows.

\section{Test Pool}

The experimental test pool had to be made from a material which would stand up to the highest temperature that the heat transfer plate would experience, approximately $1000 \mathrm{~K}$, and also allow visual observation of the phenomena. The first of these characteristics could have been met by many materials, but the second was very limiting. The material chosen was quartz, which met both requirements. Furthermore, quartz has a small coefficient of linear expansion, so that the volumetric expansion of the pool, which occurred from room temperature to the maximum operating temperature, did not cause the seals at the top and the bottom of the ponl to leak, Fig. 1. Moreover, the pool wall had to withstand the thermal shock which took place each time the experiment was started.

The cylindrical test pool stood approximately $25 \mathrm{~cm}$ high and had an inside diameter of $10.16 \mathrm{~cm}$, with a wall thickness of $0.3 \mathrm{~cm}$. At a height of $8 \mathrm{~cm}$ from the bottom of the pool there was an entrance port for the entry of makeup fluid. A stainless-steel tube was fitted through the port which directed the incoming test fluid to a height of about $2 \mathrm{~cm}$ above the heat transfer plate.

The quartz pool was sealed at its top by a stainless-steel plate and a Teflon gasket. The plate was fitted with an exit tube which led to the condensing system. The top plate secured the quartz tube to the heat transfer plate by means of four bolts. The bottom of the pool was sealed by a Durabla heat-resistant gasket, which had a thickness of approximately $0.04 \mathrm{~cm}$ and an inside diameter of $10.32 \mathrm{~cm}$. This thickness is about ten times larger then the expected thickness of the 
vapor film previously observed in film boiling (Berenson [3]). It was hoped that after film boiling started, the vapor-liquid boundary would be as close as physically possible to the inside bottom edge of the quartz pool wall. Being on the bottom edge of the wall would assure a minimum surface area for the boundary, so that the more efficient mechanism of heat release, nucleate boiling, could be minimized. Furthermore, the inside diameter of the gasket was made to be approximately $0.16 \mathrm{~cm}$ larger than the inside diameter of the pool wall so that it would be recessed back from the wall, thus eliminating a surface area over which nucleate boiling could occur. To clarify, a small gap was created between the bottom of the quartz pool wall and the heat transfer surface so that when film boiling. started the vapor-liquid boundary coincided with the bottom edge of the quartz wall, thereby minimizing the surface upon which nucleate boiling could occur.

The side wall and the top of the test pool were covered with guard heaters to ensure that there would be no subcooling between the wall and the pool. This precaution was taken so that measurements of the heat flux, during film boiling by the condensing system, would be as accurate as possible. The temperature of the pool wall was maintained close to the saturation temperature of water by monitoring the thermocouples placed between the pool wall and guard heaters.

\section{Heat Transfer Surface - Thermal Features}

From the thermocouples embedded in the heat transfer surface both the surface temperature of the plate [by extrapolation], and the heat flux through the plate [by conduction] were determined. Figure 2 shows the top view of the heat transfer plate which includes the gas holes and the placement of thermocouples. Also, Fig. 3 shows a schematic of an inside slice of the heat transfer plate with some material descriptions and pertinent dimensions. This schematic view shows how the thermocouples, gas orifices and heating coil were arranged within the plate. 
In making the heat transfer plate, two very important problems had to be addressed: 1) Would the flexible coil, used to heat the plate, create the necessary uniform temperature on the upper surface of the plate, since the coil was only in contact with the bottom of the plate at discrete locations, see Fig. 3. 2) Would the thermocouples, implanted in the plate to measure the upper-surface temperature and the heat flux through that plate, give accurate readings? Both questions were answered analytically before constructing the experimental apparatus. The following is a summary of the analyses done to answer these questions and the details can be found in Duignan [2].

It was determined from a conservative estimate that the distance between successive contacts of the coil on the plate should be approximately equal to the thickness of the heat transfer plate. This intercoil distance would give the upper heat-transfer surface a uniform temperature from one-coil contact to the next, as long as the same amount of heat was released at each point of contact. Since the filament of the heating coil had a diameter of approximately $3.2 \mathrm{~mm}$ and the heat transfer plate had a thickness of $6.35 \mathrm{~mm}$, the chosen separation between coils left a gap of approximately a one-coil diameter between successive coils. This gap was enough for the thermocouples and gas holes in the plate assembly to pass through.

For accurate temperature readings, it was important to consider how and where the thermocouples were to be located in the heat transfer plate. Because of the physical limitations in making very long, thin thermocouple wells through the stainless-steel heat transfer plate, the thermocouple leads, which extend immediately from the thermocouple bead, could not be placed radially though the heat transfer plate. Orientation of the leads along the radii would have been preferred, as then they would closely follow the isotherms in the plate. A less desirable orientation chosen was to have the leads exit the plate along a vertical axis, see Fig. 3. Placed vertically through the plate, the leads were exposed to the maximum temperature gradient in the plate, and, as such, could be an avenue 
for a differing heat flow than the one in the heat transfer plate. From the analysis, it was found that for the highest experimental plate temperature, approximately $1000 \mathrm{~K}$, the thermocouple reading would differ by approximately $0.65 \mathrm{~K}$ from the true local temperature. This temperature difference is relatively insignificant since the absolute temperatures used in this experiment were greater by three orders of magnitude. Therefore, the chosen orientation of the thermocouples was deemed acceptable for the experiment.

The last important concern about the thermocouples in the heat transfer plate is an accurate knowledge of their location from the top of the plate surface. The measured surface-to-thermocouple distance for each plate thermocouple is a summation of: 1) the distance from the top of the plate to the bottom of thermocouple well, 2) from the well bottom to the top of the thermocouple bead, and, finally, 3) the radius of the bead itself. The uncertainty in depth measurements is $0.02 \mathrm{~mm}$ and the distance from the top of the thermocouple well to the midpoint of the thermocouple bead averaged $0.25 \mathrm{~mm}$ for all twelve thermocouples.

With the knowledge of the thermocouples' locations and how much their readings differed from the true plate temperatures, both the surface temperature of plate and the heat flow through the plate could be measured once the implanted thermocouples were calibrated. A calibration showed that the "true" thermocouple temperature differed from those obtained from tabulated EMF values, published by the National Institute of Standards and Technology (NIST), by not more than $1.5 \mathrm{~K}$ over the range of experimental temperatures. Note, "true" means a reading obtained from a platinum resistance thermometer which had an accuracy of better than $0.01 \mathrm{~K}$. Because of the high plate temperature common in the film boiling of water, above $500 \mathrm{~K}$, this $1.5 \mathrm{~K}$ maximum temperature difference was considered insignificant and therefore the NIST tabular values were applied directly to determine the thermocouple temperature from its voltage output. 


\section{Heat Transfer Surface - Physical Features}

As illustrated in Fig. 2 the heat transfer surface had nine $1-\mathrm{mm}$ drilled holes through which nitrogen was injected into the overlying pool. The holes were drilled in a square geometry with the closest center-to-center hole spacing being $27.2 \mathrm{~mm}$. This inter-hole distance was chosen to be equal to the "most dangerous" wavelength, $\lambda_{\mathrm{d}}=2 \pi\left[3 \sigma /\left(\mathrm{g}\left(\rho_{1}-\rho_{f}\right)\right)\right]^{1 / 2}$, first mentioned by Bellman and Pennington [4], which is based on the Taylor [5] instability theory. The actual configuration of the gas holes conform to the bubble release pattern described by Sernas et al. [6] and observed by Duignan et al. [7].

The heat transfer plate itself was a circular flat disk made of 304 stainless steel which was $6.35-\mathrm{mm}$-thick and polished to minimize thermal radiation. The size of the surface, $101.6 \mathrm{~mm}$ diameter, was chosen to be considered "large" with respect to film boiling. Kesselring et al. [8] showed that when the smallest horizontal dimension of a flat heat transfer surface is less than approximacely $2 \lambda_{d}$, the film boiling heat transfer becomes a function of the surface geometry, similar to that experienced when changing the diameter of a tube heater (Lienhard and Wong [9]). Klimenko [10] also noted the importance of the size of the heat transfer surface and proposed that when the surface dimension $D$ is greater than $2.8 \lambda_{d}$, the surface is considered "large" and any further increase in size will not affect the heat transfer. Since $\lambda_{d}$ is equal to $27.2 \mathrm{~mm}$ for water [at the surface superheats of concern] the surface, $\mathrm{D}=101.6 \mathrm{~mm}$, is considered to be large by both criteria.

\section{Condensing System}

Besides calculating the heat conduction through the heat transfer plate, another means used to obtain the heat flux was by measuring the mass of water vapor leaving the boiling chamber. This was done by condensing the vapor and measuring the rate at which water left the system. After eliminating the sources of superheating and subcooling water in the test pool, this mass flux measurement 
became the most accurate and primary means of measuring heat flux. Moreover, the assessment of heat flux based on the collected condensate was inherently more stable than the method of heat conduction. Small changes in the temperature of the heat transfer plate led to large changes in the axial temperature gradient through the plate, and hence, large fluctuations in the inferred heat flux by conduction.

Figure 1 shows a schematic on how the condensing system was setup. Care was taken to make sure that the condensers completely condensed all the water vapor, while not significantly increasing the pressure in the boiling chamber, which would have changed the saturation temperature of the water. The pressure in the test pool was periodically checked and found to be approximately $5 \mathrm{~cm}$ of $\mathrm{H}_{2} \mathrm{O}$ above atmospheric pressure, not enough to change significantly the saturation temperature from the value at atmospheric pressure. Total condensation was checked by measuring the temperature of the exiting mixture of nitrogen, water vapor, and water.

The only other concern in the measurement of mass flux was the loss of water which left the condensing system with the nitrogen. To this end, the water vapor contained in the saturated nitrogen gas leaving the condenser, was taken into account. Furthermore, the escaping nitrogen was checked to see if it was transporting, water droplets. It was found that 10 perceptible water, in the form of liquid, left with the gas below superficial gas velocities of approximately $10 \mathrm{~cm} / \mathrm{s}$.

\section{Gas Flow System}

The non-condensible gas-flow system shown in Fig. 1 consisted of a gas supply reservoir, a pressurized metering system, and an in-line gas heater. The in-line gas heater ensured that gas entering the experimental apparatus was approximately at the temperature of the heat transfer plate. Even though the heat capacity of the nitrogen is insignificant with respect to the stainless-steel apparatus or the water in the bubbling pool, its entering the system at the 
temperature of the plate ensured that no local cooling would occur around the jet holes, which might have created instabilities.

The gas flow rate was measured by a rotameter which was metered at $0.276 \mathrm{MPa}$ above atmospheric pressure to ensure a smooth flow through the meter. To approximately maintain the same pressure drop across all the jet holes in the heat transfer plate a gas plenum was used, which also included a thermocouple to monitor the temperature of the incoming gas.

\section{Data Acquisition System}

The system was controlled by interactive software, which received transfer parameters from the experimenter and scanned data channels upon command. The twelve thermocouples of the heat transfer plate were read sequentially at 0.1 second intervals during one minute. A one-minute interval gave fifty temperature values for each thermocouple, which were averaged to give a resulting temperature. All thermocouple outputs were measured by a programmable digital voltmeter with a resolution of 1 microvolt, and the thermocouple scanning time was 1 millisecond per channel.

\section{RESULTS AND DISCUSSION}

The primary goal was to develop a database for gas-fluxenhanced film boiling. To that end, this section presents the data on the heat flux and then the correlation of those data to a semiempirical model. These results are for water pools greater than 10 $\mathrm{cm}$ in height.

\section{Database On Gas-Flux-Enhanced Film Boiling}

Figure 4 shows the actual measured heat flux as a function of the superficial gas velocity [the total volumetric gas flux divided by the heat transfer surface area] with surface superheat as the parameter. The figure depicts the experimental data which can be found in Duignan [2]. 
The ranges of the data shown in Fig. 4 for both the surface superheat, $\Delta \mathrm{T}_{S A T}$, and superficial gas velocity, $j_{g}$, were not arbitrarily chosen, but were set by the physical limitations of the experimental apparatus and the phenomena being measured. For the lowest superheats, $159 \mathrm{~K}$ and $211 \mathrm{~K}$, the data do not extend over the entire range of $j_{g}$. At the lower superheats, care had to be taken not to fall out of film boiling because of the proximity to the minimum film boiling point (MFB). For water at atmospheric pressure, Hosler and Westwater [11] measured the MFB to be at a surface superheat of $158 \mathrm{~K}$; Nishikawa et al. [12] observed $\Delta \mathrm{T}_{\min } \sim 110 \mathrm{~K}$. One criterion by Poniewski [13] for film boiling postulates that when the surface temperature is below the liquid critical temperature, and above that at the MFB, a small percentage of liquid still touches the heat transfer surface [for water: $\mathrm{T}_{\text {CRITICAL }} \sim 647 \mathrm{~K}$ or $\Delta \mathrm{T}_{\mathrm{SAT}} \sim 274 \mathrm{~K}$ ]. With the introduction of gas jets from the surface, the physical situation becomes more unstable and possibly leads to a higher percentage of liquid touching the surface. At a constant heat flux, increasing the amount of liquid solid contacts will eventually cause a spontaneous shift from film boiling to transition boiling and, finally, to nucleate boiling. In other words, it appears that the required surface superheat at the MFB increases with increasing $j_{g}$ because of the increased instability caused by the jets. For surface superheats of $159 \mathrm{~K}, 211 \mathrm{~K}$, and $271 \mathrm{~K}$ film boiling could not be maintained for approximately $\mathrm{j}_{\mathrm{g}}>1 \mathrm{~cm} / \mathrm{s}, \mathrm{j}_{\mathrm{g}}>4 \mathrm{~cm} / \mathrm{s}$, and $\mathrm{j}_{\mathrm{g}}>10.5 \mathrm{~cm} / \mathrm{s}$, respectively.

Another physical limitation was the surface superheat. Accurate heat transfer measurements could not be made for surface superheats greater than approximately $650^{\circ} \mathrm{C}$ because of the presence of nucleate boiling on the boiling pool wall. Care was taken to minimize any nucleate boiling by external cooling around the base of the test pool, but when the surface temperature of the heat transfer plate rose above $650^{\circ} \mathrm{C}$, its occurrence was unavoidable. Also of concern at high temperatures was the oxidation of the heat transfer surface that occurred during the several hours needed for 
each experimental run. Below a surface temperature of about $650^{\circ} \mathrm{C}$, the plate was minimally oxidized and could be cleaned off by the removal of a negligible amount of surface metal. This ensured that the plate-to-thermocouple distances were negligibly affected; thus, accurate temperature extrapolations could be made.

The last limitation was for superficial gas velocities above $9 \mathrm{~cm} / \mathrm{s}$. At about $\mathrm{j}_{\mathrm{g}}=9$ or $10 \mathrm{~cm} / \mathrm{s}$, nitrogen flowed through the condensing system at a rate which caused droplets of water to be carried through the system with the gas, and consequently, were not captured in the collection system. To measure the data as accurate $y$ as possible, most measurements were made for superficial gas velocities under $8.5 \mathrm{~cm} / \mathrm{s}$.

Figure 4 also includes the measured values for the heat flux with no gas emerging from the heat transfer plate. These values were obtained from a previous investigation with a similar experimental apparatus, ref. [14]. For the present experimental apparatus the lowest superficial gas velocity that could be sustained was approximately $0.6 \mathrm{~cm} / \mathrm{s}$. Below this velocity some of the gas jets stopped bubbling and a further reduction in the gas flow would have caused back-flooding into the gas plenum through the $1-\mathrm{mm}$ diameter jet holes.

Figure 4 shows that the non-condensible gas enhances the heat flux from the heat-transfer surface, at all superheats. Unfortunately, the trend of this heat flux increase is not evident over the range of gas velocities measured. It appears that the slope of the data decreases with increasing superficial gas velocity, leading to a possible conclusion that the heat flux reaches an asymptotic value at large gas velocities. The fact that the heat flux becomes a weak function of the gas velocity is consistent with pool bubbling, see ref. [15]. Even so, there is no basis for extrapolating the observed trend of the data beyond the range of gas velocities actually tested since a 
flow regime transition from bubbly flow to churn-turbulent flow is expected for a superficial gas velocity of approximately $10 \mathrm{~cm} / \mathrm{s}$.

\section{Correlation of Experimental Data to the Semi-Empirical Model}

To facilitate the use of the experimental database a semiempirical model was developed and correlated with the data. As a starting point to the model development an asymptote of enhancedfilm-boiling heat transfer by gas injection was studied [i.e., stable film boiling, which exists when no gas injection emerges from the heat transfer surface]. A model exists for film boiling on horizontal flat surfaces which is based on the thermodynamic considerations of Bromley [16] and the hydrodynamic considerations of Berenson [3], i.e.,

$$
\begin{gathered}
\mathrm{q}_{\mathrm{FB}}\left(\mathrm{j}_{\mathrm{g}}=0\right)=\mathrm{h}_{\mathrm{FB}}\left(\mathrm{j}_{\mathrm{g}}=0\right) \Delta \mathrm{T}_{\mathrm{SAT}}= \\
\beta\left[\mathrm{k}_{f}^{3} \mathrm{~g} \rho_{f}\left(\rho_{\mathrm{l}}-\rho_{f}\right) \mathrm{h}_{\mathrm{fg}} * /\left(\mu_{f} \Delta \mathrm{T}_{\mathrm{SAT}} \mathrm{D}_{l}\right)\right]^{1 / 4} \Delta \mathrm{T}_{\mathrm{SAT}}
\end{gathered}
$$

where $\quad \beta=$ coefficient to be determined by correlation

$$
\begin{aligned}
& \mathrm{h}_{\mathrm{fg}}{ }^{*}=\mathrm{h}_{\mathrm{fg}}(1+0.5 \mathrm{Ja})=\text { modified latent heat } \\
& \mathrm{D}_{\mathrm{l}}=\left[\sigma /\left(\mathrm{g}\left(\rho_{\mathrm{l}}-\rho_{f}\right)\right)\right]^{1 / 2}=\text { Laplace reference length }
\end{aligned}
$$

Berenson correlated equation (1) to his heat transfer data, ref. [17], and determined the coefficient to be 0.425 , which he stated is within \pm 10 percent of his experimental data. This accuracy has been shown to be true by other studies [e.g., Nishikawa et al. [18], Ramilison and Lienhard [19] near the minimum film boiling point]. It needs to be pointed out that equation (1) does not include the effect of thermal radiation from a heat transfer surface. To include radiation, Bromley [16] proposed the following model,

$$
q=\left(q_{F B}{ }^{4} / q\right)^{1 / 3}+q_{\text {RADIATION }}
$$

He further suggested that heat transfer by thermal radiation could be determined by using a parallel plate model, i.e., 


$$
\mathrm{q}_{\text {RADIATION }}=\sigma_{\mathrm{SB}}\left[1 / \varepsilon_{\text {SURF }}+1 / \varepsilon_{1}-1\right]^{-1}\left(\mathrm{~T}_{\text {SURF }}{ }^{4}-\mathrm{T}_{\mathrm{SAT}}{ }^{4}\right)
$$

An analysis by Sparrow [20] determined equations (2) and (3) to accurately represent the contribution of radiation to the film boiling heat transfer. With respect to the radiative participation of water vapor in the vapor film, he concluded that the emissivity of steam at atmospheric pressure on the heat transfer is completely negligible (less than 0.01$)$, because of the thin film typical of film boiling $(\sim 0.25$ to $0.50 \mathrm{~mm}$ ).

In summary, equation (2) can be used to determine the total heat transfer for film boiling from a flat horizontal surface to an overlying liquid pool at its saturation temperature, which would include the effect of radiation.

Using the modeling that resulted in equation (1) a model was developed, Duignan [2], that included the vapor mass being entrained away from the vapor film because of the presence of gas jets emerging from the heat transfer surface. It was proposed that the entrained mass from the vapor film reduces the film thickness between the heat transfer surface and the overlying liquid pool, from that which would exist in stable film boiling. This reduced thickness means less resistance to the flow of heat, therefore more liquid is transformed into vapor. The result of the modeling is,

$$
\begin{gathered}
\mathrm{q}_{\mathrm{FB}}=\mathrm{h}_{\mathrm{FB}} \Delta \mathrm{T}_{\mathrm{SAT}}= \\
\left(\beta_{\mathrm{I}} \mathrm{j}_{\mathrm{g}}+\beta_{\mathrm{II}}\right)^{1 / 4}\left[\mathrm{k}_{f}^{3} \mathrm{~g} \rho_{f}\left(\rho_{\mathrm{l}}-\rho_{f}\right) \mathrm{h}_{\mathrm{fg}} * /\left(\mu_{f} \Delta \mathrm{T}_{\mathrm{SAT}} \mathrm{D}_{\mathrm{I}}\right)\right]^{1 / 4} \Delta \mathrm{T}_{\mathrm{SAT}}
\end{gathered}
$$

The coefficient $\beta_{\mathrm{II}}^{1 / 4}$ was set equal to the Berenson coefficient, 0.425 , so that equation (4) reduces to equation (1) when the superficial gas velocity, $j_{g}$, is zero. 
Note, the cuefficient of (4) is non-dimensional since the terms in the brackets together form the dimensions of $h^{4}$. This fact can be seen directly by grouping the non-dimensional terms, i.e.,

$$
\mathrm{Nu}_{f}=\left(\beta_{\mathrm{I}} \mathrm{j}_{\mathrm{g}}+\beta_{\mathrm{II}}\right)^{1 / 4}\left[\mathrm{Gr} \operatorname{Pr} / \mathrm{Ja}^{*}\right]_{f}^{1 / 4}
$$

where,

$$
\begin{aligned}
& \mathrm{Nu}_{f}=\mathrm{h}_{\mathrm{FB}} \mathrm{D}_{1} / \mathrm{k}_{f}=\text { Nusselt Number } \\
& \mathrm{Gr}=\mathrm{D}_{1}^{3} \mathrm{~g}\left[\left(\rho_{1} / \rho_{f}\right)-1\right] / v_{f}{ }^{2}=\text { Grashof Number } \\
& \mathrm{Pr}=\mu_{f} \mathrm{c}_{\mathrm{p}_{f}} / \mathrm{k}_{f}=\text { Prandtl Number } \\
& \mathrm{Ja}^{*}=\mathrm{c}_{\mathrm{p}_{f}} \Delta \mathrm{T}_{\mathrm{SAT}} / \mathrm{h}_{\mathrm{fg}}{ }^{*}=\text { Modified Jacob Number }
\end{aligned}
$$

That is, while $\beta_{\mathrm{II}}$ is dimensionless so is the group $\beta_{\mathrm{I}} \mathrm{j}_{\mathrm{g}}$ with $\beta_{\mathrm{I}}$ taking on the reciprocal dimensions of $\mathrm{j}_{\mathrm{g}}$. Normalizing equation (4) to the Berenson equation, i.e., at $j_{g}=0$, for the same superheat gives a convenient form for correlation:

$$
\begin{aligned}
& \mathrm{Nu}_{f}\left(\mathrm{j}_{\mathrm{g}}\right) / \mathrm{Nu}_{f}\left(\mathrm{j}_{\mathrm{g}}=0\right)=\mathrm{h}_{\mathrm{FB}} / \mathrm{h}_{\mathrm{FB}}\left(\mathrm{j}_{\mathrm{g}}=0\right)=\mathrm{q}_{\mathrm{FB}} / \mathrm{q}_{\mathrm{FB}}\left(\mathrm{j}_{\mathrm{g}}=0\right)= \\
&\left(1+\beta_{\mathrm{I}} \mathrm{j}_{\mathrm{g}} / \beta_{\mathrm{II}}\right)^{1 / 4}
\end{aligned}
$$

Before determining $\beta_{I}$ from correlation with the data, the measured heat flux shown in Fig. 4 has to be reduced by the heat flux due to radiation using equation (2). As the Berenson relation, equation (1), equation (4) does not include the effect of thermal radiation. [Sources for the properties shown in equation (1) and the radiative properties in equation (3) are cited in Duignan [2]; for the vapor-liquid interface of water, $\varepsilon_{1}$ was assumed to remain constant at 0.96. The emittance of the heat transfer plate was assumed to be that of a polished surface and a function of temperature. At the lowest surface superheat $\varepsilon_{\text {SURF }} \sim 0.11$ and at the highest $\varepsilon_{\text {SURF }} \sim 0.27$ ].

Figure 5 is dimensionless, so that any dimensional quantity can be used for $\beta_{\mathrm{I}}$ and $\mathrm{j}_{\mathrm{g}}$. Moreover, as shown in Fig. 4, the dimensions $[\mathrm{cm} / \mathrm{s}]$ are used for $j_{g}$ because of its common use in the literature. The coefficient was determined by correlating the data so that the 
sum of the squared differences between the model and the data was minimized. The result is:

$$
\beta_{1}=0.068(\mathrm{~cm} / \mathrm{s})^{-1}
$$

and $\beta_{\mathrm{I}}$ has a standard deviation of $0.005(\mathrm{~cm} / \mathrm{s})^{-1}$ and for a $99 \%$ confidence level has a range of $\left[0.053(\mathrm{~cm} / \mathrm{s})^{-1}, 0.083(\mathrm{~cm} / \mathrm{s})^{-1}\right]$. To reiterate, this correlation was based on all of the measured data after subtracting the radiation contribution to the total heat flux.

Superimposed on the correlated data in Fig. 5 is a solid line and a shaded area. The solid line represents a perfect correlation to the model and the shaded area is $\pm 15 \%$ region, which encompass over $90 \%$ of the experimental data. The difference of the data from the correlation line cannot be explained by the systematic or random errors in the data, as seen in ref. [2]. Ruling out these two possible sources of error it is concluded that the observed differences must emanate from the inadequacies of the semi-empirical model, equation (4).

Based on the similar fluctuations of the heat flux data around $\mathrm{Nu} / \mathrm{Nu}\left(\mathrm{j}_{\mathrm{g}}=0\right)=\mathrm{q}_{\mathrm{FB}} / \mathrm{q}_{\mathrm{FB}}\left(\mathrm{j}_{\mathrm{g}}=0\right)=1$, as seen in Fig. 5, to the widely accepted Berenson [3] model, then equation (4) adequately represents the experimental data when radiation is negligible or when the component of the heat transfer, due to radiation, is removed from the total heat flux.

\section{CONCLUSIONS}

1.) Over the range of superficial gas velocities used, the effect of the gas jetting on the film boiling was to increase the surface heat transfer, at a constant surface superheat. The increase is approximately two-fold over heat transfer without gas jetting at superficial gas velocity of $8.5 \mathrm{~cm} / \mathrm{s}$. 
2.) The heat transfer is increased by gas jetting at all the surface superheats observed.

3.) When the surface superheat is close to the minimum film-boiling point, the introduction of the gas jets tends to cause the film to collapse to nucleate boiling, unless the surface temperature is increased. This finding suggests that the required minimum film boiling superheat may increase with an increase in superficial gas velocity.

4.) The semi-empirical model, equation (4), represents film boiling with gas jetting for water with an uncertainty of $\pm 15 \%$.

It is generally concluded that when there is a surface over which film boiling occurs and from which gas jets emerge, the actual heat transfer from that surface can only be accurately ascertained when including the effects of those jets. Equation (4) is a useful approximation to the enhancement of film boiling heat transfer caused by jetting.

\section{ACKNOWLEDGMENTS}

This work was performed under the auspices of the U.S. Nuclear Regulatory Commission.

\section{REFERENCES}

1. R. E. Blose, J. E. Gronager, A. J. Suo-Anttila and J. E. Brockmann, SWISS: Sustained Heated Metallic Melt/Concrete Interactions with Overlying Water Pools, Sandia National Laboratories, NM, NUREG/CR4727 (1987).

2. M. R. Duignan, Enhanced Convective and Film Boiling Heat Transfer by Surface Gas Injection, PhD thesis, Dept. of Mechanical Engineering, State University of New York at Stony Brook, New York (1989). 
3. P. J. Berenson, Film-Boiling Heat Transfer from a Horizontal Surface, J. Heat Transfer, 83, 351-358 (1961).

4. R. Bellman and R. H. Pennington, Effects of Surface Tension and Viscosity on Taylor Instability, Quar. Appl Math., 12, 151-162 (1954).

5. G. I. Taylor, The Instability of Liquid Surfaces When Accelerated in a Direction Perpendicular to Their Plane, Proc. Roy. Soc., ser. A (London), 201, 192-196 (1950).

6. V. Sernas, J. H. Lienhard and V. K. Dhir, The Taylor Wave Configuration During Boiling from a Flat Plate, Int. J. Heat Mass Transfer, 16, 1820-1821 (1973).

7. M. R. Duignan, G. A. Greene and T. F. Irvine, Jr., Measurements of the Film Boiling Bubble Parameters on a Horizontal Plate, Int. Comm. Heat Mass Transfer, 16(3), 355-366 (1989).

8. R. C. Kesselring, P. H. Rosche and S. G. Bankoff, Transition and Film Boiling from Horizontal Strips, A.I.Ch.E. Journál, 13, 669-675 (1967).

9. J. H. Lienhard and P. T. Y. Wong, The Dominant Unstable Wavelength and Minimum Heat Flux During Film Boiling on a Horizontal Cylinder, J. Heat Transfer, 86, 220-226 (1964).

10. V. V. Klimenko, Film Boiling on a Horizontal Plate - New Correlation, Int. J. Heat Mass Transfer, 24, 69-79 (1981).

11. E. R. Hosler and J. W. Westwater, Filming Boiling on a Horizontal Plate, ARS Journal, 32, 553-558 (1962).

12. K. Nishikawa, S. Hasegawa, N. Kitayama and T. Sakamoto, The Effect of Heating Surface Conditions on the Transition Boiling - The Investigation of Transition Boiling (2nd Report) -, Technol. Reports Kyushu Univ., Vol. 38, pp. 399-404 (1966). 
13. M. Poniewski, Dissipative Model of Film Boiling Crisis, Int. J. Heat Mass Transfer, 30, 1847-1857 (1987).

14. M. R. Duignan, G. A. Greene and T. F. Irvine, Jr., Film Boiling Heat Transfer to Large Superheats From a Horizontal Flat Surface, J. Heat Transfer, 113, 266-268 (1991).

15. M. R. Duignan, G. A. Greene and T. F. Irvine, Jr., Heat Transfer from a Horizontal Bubbling Surface to an Overlying Water Pool, Chem. Eng. Comm., 87, 185-194 (1990).

16. L. A. Bromley, Heat Transfer in Stable Film Boiling, PhD thesis, Department of Chemisty, University of California, Berkeley, California (1948).

17. P. J. Berenson, Experiments on Pool-Boiling Heat Transfer, Int. J. Heat Mass Transfer, 5, 985-999 (1962).

18. K. Nishikawa, S. Hasegawa, T. Iwabuchi and Y. Miyabara, Y., Characteristics of Transition Boiling on the Horizontal Plate, Technol. Reports Kyushu Univ., Vol. 38, pp. 306-310 (1965).

19. J. M. Ramilison and J. H. Lienhard, Transition Boiling Heat Transfer and the Film Transition Regime, J. Heat Transfer, 109, 746752 (1987).

20. E. M. Sparrow, The Effect of Radiation on Film boiling Heat Transfer, Int. J. Heat Mass Transfer, 7, 229-237 (1964). 


\section{NOMENCLATURE}

$\begin{array}{ll}\mathrm{c}_{\mathrm{p}} & \text { specific heat capacity } \\ \mathrm{D} & \text { diameter of heating surface } \\ \mathrm{D} & \text { Laplace reference length } \\ \mathrm{g} & \text { acceleration of gravity } \\ \mathrm{Gr} & \text { Grashof number } \\ \mathrm{h} & \text { heat transfer coefficient } \\ \mathrm{h}_{\mathrm{fg}} & \text { latent heat } \\ \mathrm{h}_{\mathrm{fg}}{ }^{*} & \text { modified latent heat } \\ \mathrm{Ja}^{\mathrm{a}} & \text { Jacob number } \\ \mathrm{Ja} a^{*} & \text { modified Jacob number (defined for Equation } 5 \text { ) } \\ \mathrm{j}_{\mathrm{g}} & \text { superficial gas velocity } \\ \mathrm{k} & \text { thermal conductivity } \\ \mathrm{Nu} & \text { Nusselt number } \\ \mathrm{Pr} & \text { Prandtl number } \\ \mathrm{q} & \text { heat flux } \\ \mathrm{T} & \text { temperature } \\ \Delta \mathrm{T}_{\mathrm{SAT}} & \text { superheat, }\left(\mathrm{T}_{\text {SURF }}-\mathrm{T}_{\mathrm{SAT}}\right)\end{array}$

\section{Greek Symbols}

$\beta, \beta_{\mathrm{I}}, \beta_{\mathrm{II}}$ coefficients

E surface emittance

$\lambda$ Taylor wavelength

$\mu \quad$ dynamic viscosity

$v \quad$ kinematic viscosity

$\rho$ density

$\sigma \quad$ surface tension

$\sigma_{\mathrm{SB}} \quad$ Stefan-Boltzmann constant

\section{Subscripts}

d most dangerous 2 dimensional theoretical wavelength

$f \quad$ film

FB film boiling

g gas

1 liquid 
SAT saturation

SURF surface 


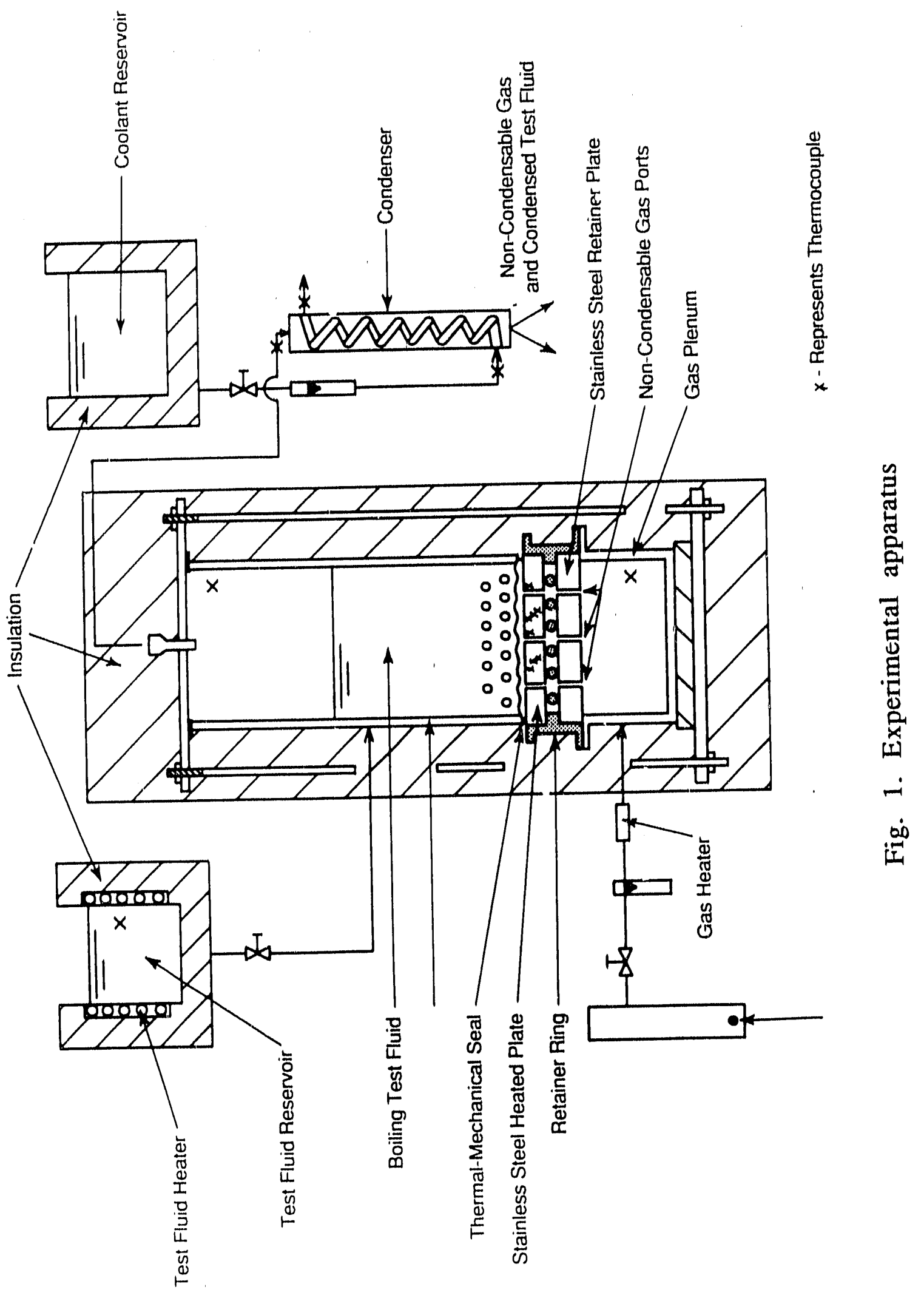




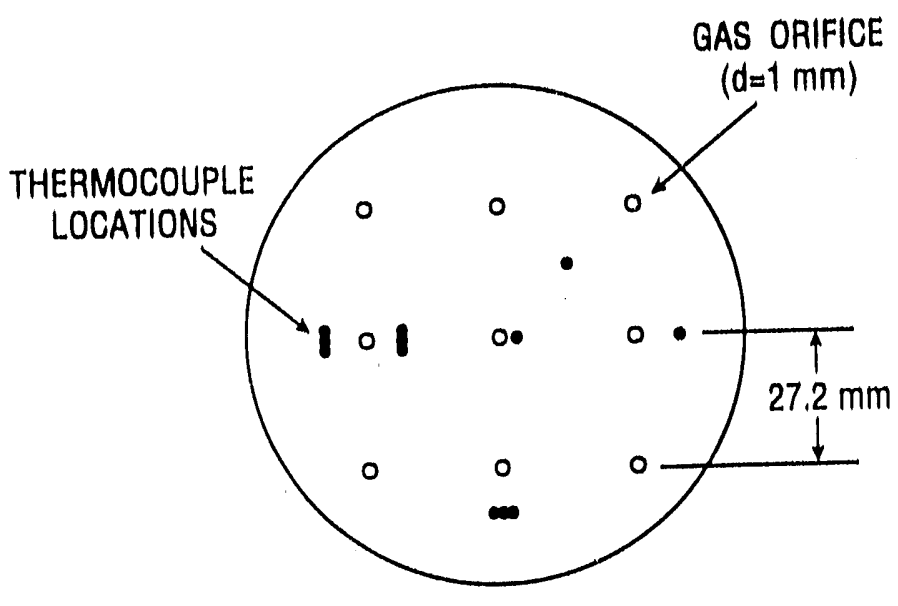

Fig. 2. Top surface of the heat transfer plate 


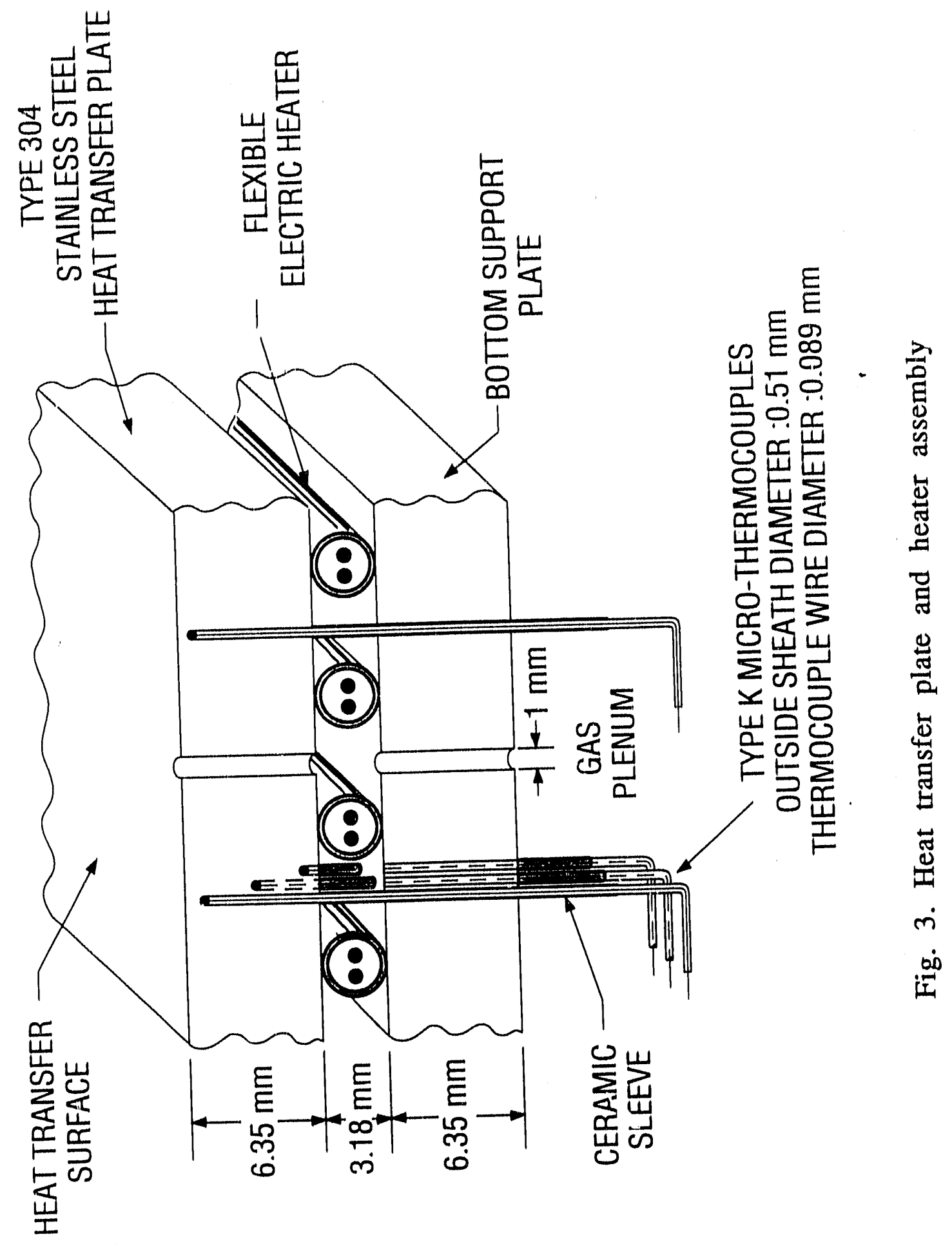




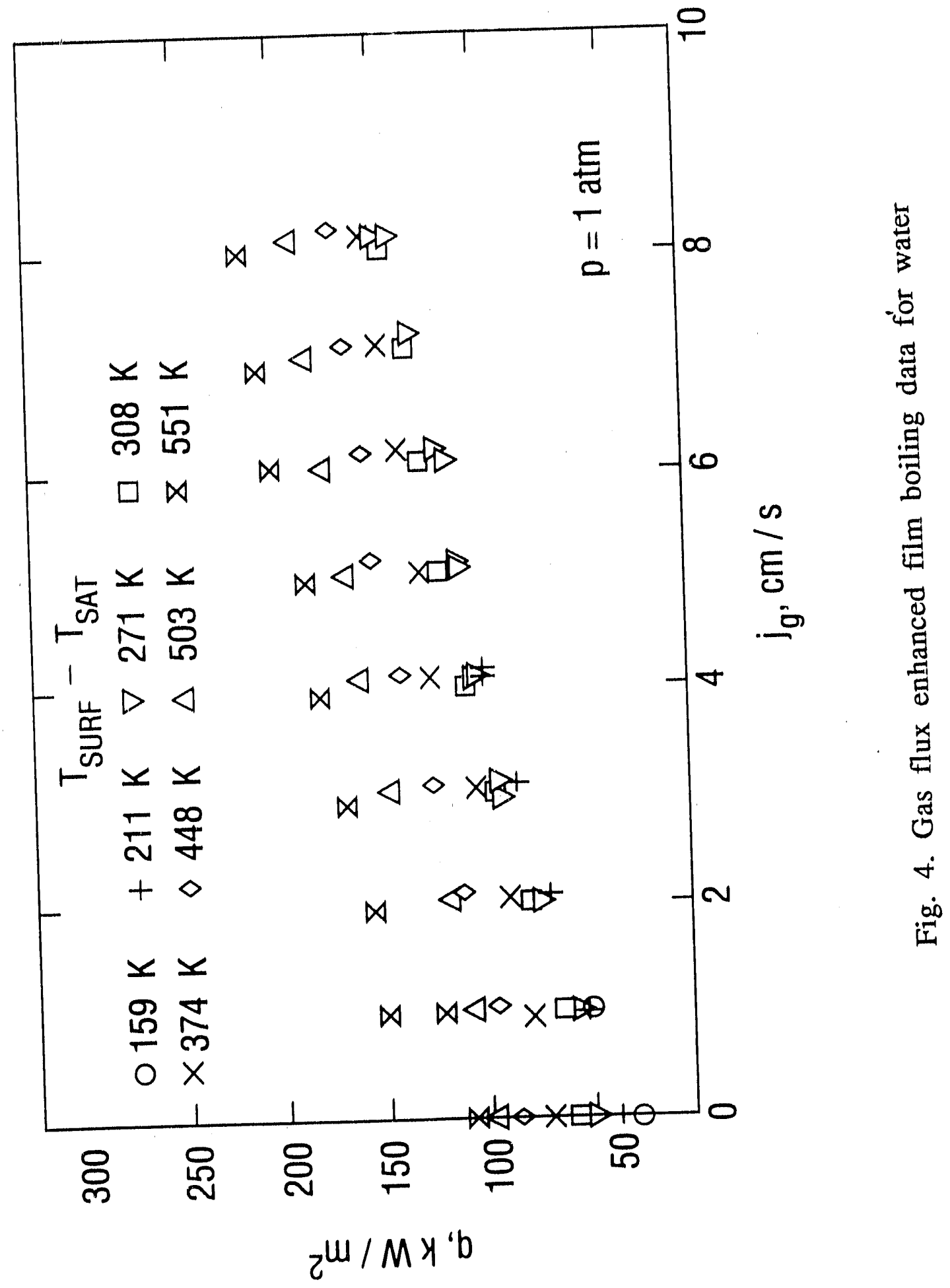




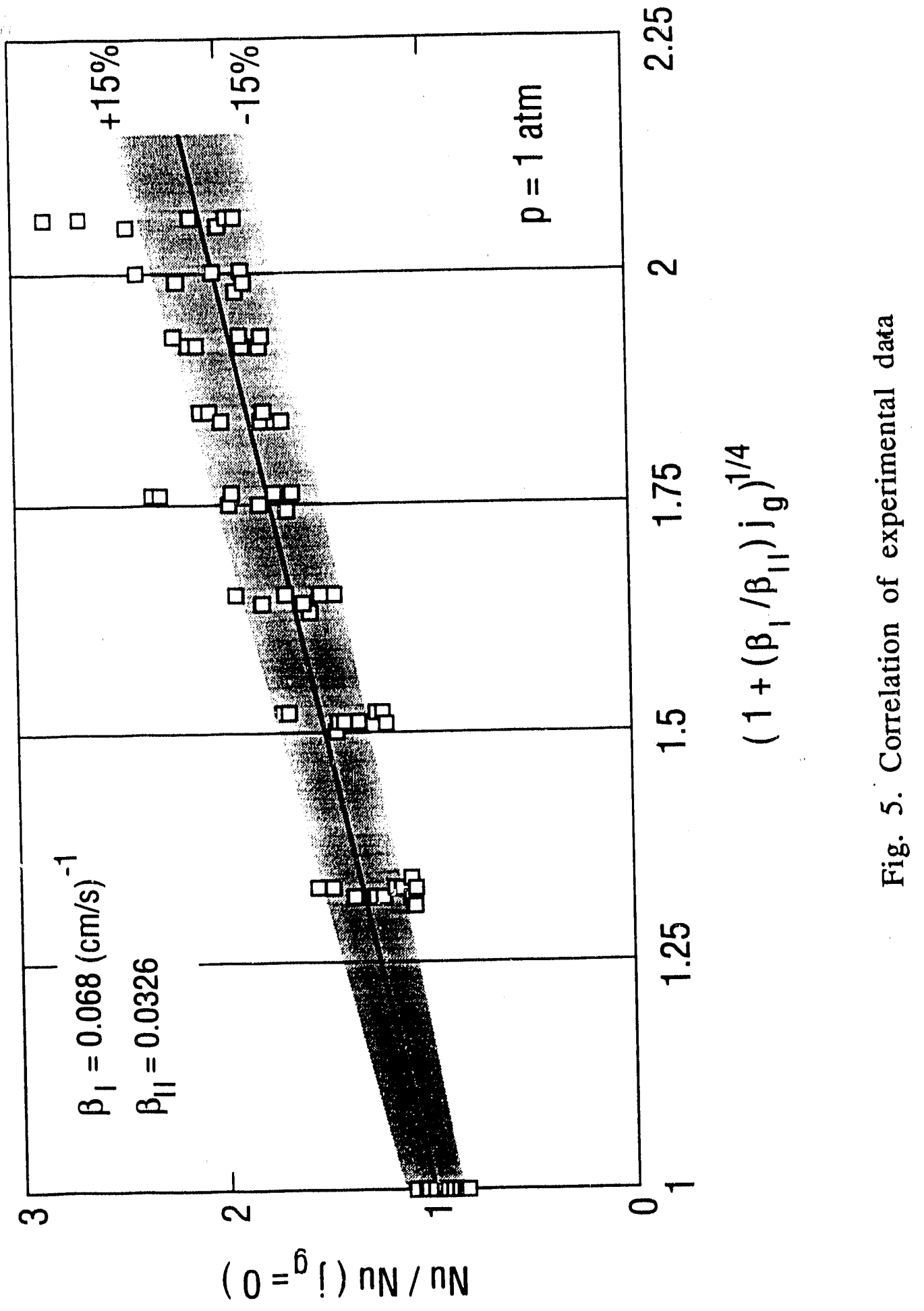



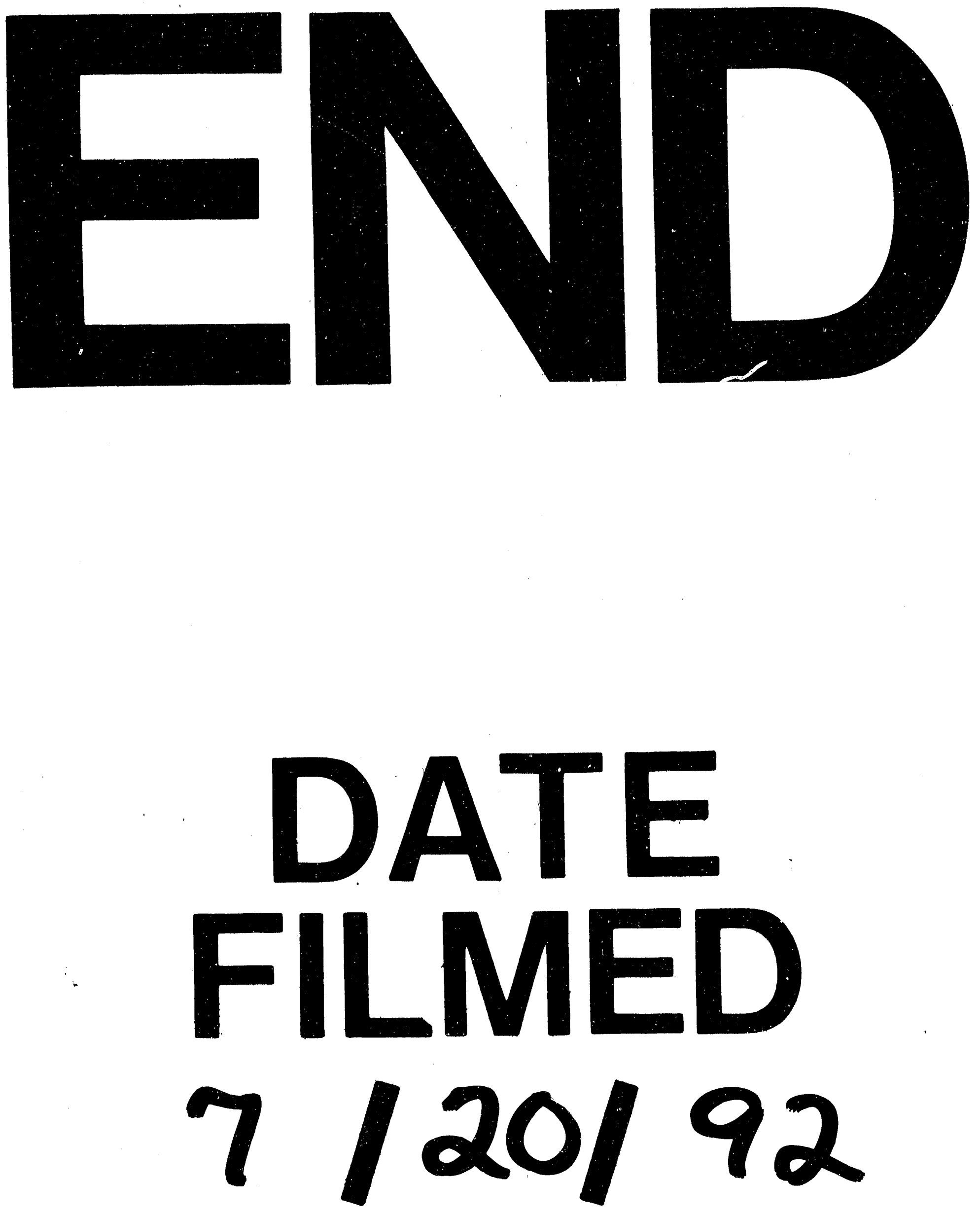

I 
